\title{
Temporal lead contamination and health risks of geophagia in Eldoret Municipality, Kenya
}

\author{
Damaris Salee NTHENYA ${ }^{1}$, Gelas Muse SIMIYU ${ }^{1 *}$ and Thomas Mutuku MUNYAO ${ }^{2}$ \\ ${ }^{I}$ School of Environmental Studies, Moi University, Environmental Biology and Health Department, Box 3900, \\ Eldoret, Kenya. \\ ${ }^{2}$ School of Environmental Studies, Moi University, Environmental Earth Sciences Department, Box 3900, \\ Eldoret, Kenya. \\ ${ }^{*}$ Corresponding author, E-mail: gelasmuse@yahoo.com, Tel: +2540722668822
}

\begin{abstract}
In Kenya, geophagic soils have been commercialised and are currently packaged and sold in supermarkets or sold in open markets where they are exposed for long periods to environments with high probability of contamination such as vehicular lead. This study assessed concentration levels of lead $(\mathrm{Pb})$ at source (Gituro quarry, Eldoret) and temporal $\mathrm{Pb}$ contamination of exposed geophagic soils sold in open markets in Eldoret Municipality. The results showed that mean $\mathrm{Pb}$ levels in the soil samples were all above naturally occurring levels indicating contamination from environmental sources. Lead concentration was lowest at source, and ranged from $31.5 \mathrm{mg} / \mathrm{kg}-41 \mathrm{mg} / \mathrm{kg}$ with a mean of $32.5 \pm 2.2 \mathrm{mg} / \mathrm{kg}-37.5 \pm 2.1 \mathrm{mg} / \mathrm{kg}$. Exposed soils had highest $\mathrm{Pb}$ concentration at Langas site with a range of $57.5 \mathrm{mg} / \mathrm{kg}-98.0 \mathrm{mg} / \mathrm{kg}$ while Huruma, Municipal market (1), and Municipal market (2) sites ranged from $46.5 \mathrm{mg} / \mathrm{kg}-73.5 \mathrm{mg} / \mathrm{kg} \mathrm{Pb}, 36.5$ $\mathrm{mg} / \mathrm{kg}-84.5 \mathrm{mg} / \mathrm{kg} \mathrm{Pb}$ and $55.0 \mathrm{mg} / \mathrm{kg}-66.0 \mathrm{mg} / \mathrm{kg} \mathrm{Pb}$ respectively. Regression of Pb levels with time gave strong positive relationships indicating temporal $\mathrm{Pb}$ accumulation. Health risk assessment showed that geophagia is a potential health hazard especially for soils exposed over a longer time in the open market. Geophagic soils sold at the open markets should be avoided.
\end{abstract}

(C) 2010 International Formulae Group. All rights reserved.

Keywords: soils, environment, vehicular emissions, consumption, effects

\section{INTRODUCTION}

Geophagia is the deliberate ingestion of soil that has been practiced for centuries. Though it occurs throughout the world and is found in both sexes of all age groups, the practice is nevertheless most dominant in children and expectant women. The reasons for this behaviour are poorly understood (Wiley and Katz, 1998) but suggestions indicate that psychological upsets and physiological changes during pregnancy could motivate geophagia. In modern human societies, the practice of geophagia represents a complex eating behaviour with an obscure aetiology including physiological, psychological, cultural, religious and medicinal beliefs. Different types of soil are preferred because of variations in tastes and individual peoples' cravings. 
Pollution of the environment over and above the background levels by heavy metals such as $\mathrm{Pb}$ emanating from human activities is now a worldwide problem. After release to the environment, the heavy metals become available for soil reactions through a variety of processes such as cationic exchange and complexation with organic ligands depending on the soils $\mathrm{pH}$, the availability of adsorption sites and ligand binding capacity (Abrahim, 2008).

About a quarter of the $\mathrm{Pb}$ added in fuels as additives is retained within the exhaust systems and engine oil of motor vehicles while the remainder is discharged via the exhaust mainly in form of fine particles of $\mathrm{Pb}$ compounds. Half of the $\mathrm{Pb}$ particulate matter falls to the ground and is dispersed in the soil while finer particles are dispersed in atmosphere and carried through considerable distances (Atkinson et al., 1999). Lead is naturally present in all soils, typically in the range of less than 10-30 mg/kg (EPA, 2001). The amounts in the top soil layers however vary widely and can be much higher due to human activities. Onyari et al. (1991) indicated that $\mathrm{Pb}$ levels in soils within the city of Nairobi ranged from 137 - $2196 \mathrm{mg} / \mathrm{kg}$ with a mean of $659 \mathrm{mg} / \mathrm{kg}$ due to vehicular emissions, while in industrial area, the levels ranged from $148-4088 \mathrm{mg} / \mathrm{kg}$ with a mean of $624 \mathrm{mg} / \mathrm{kg}$. Roundabouts, bus stations and other areas of the city characterised by heavy motor traffic showed high values.

With elevated levels in the environment, $\mathrm{Pb}$ moves along various pathways of human exposure (Figure 1), enters the food chain and gains entry into the human body (Mushak, 1998). Once in the body, $\mathrm{Pb}$ has deleterious health effects including neurotoxic effects, anemia, maternal and neonatal lead poisoning, and kidney damage, affecting the entire body (Ellen, 1993). Hooda et al. (2002), studied In vitro effects of geophagia and noted that it can potentially reduce the absorption of nutrients such as $\mathrm{Cu}, \mathrm{Zn}, \mathrm{Fe}$ and $\mathrm{Mg}$, a phenomenon that increases the bioavailability and adsorption of $\mathrm{Pb}$ in the gut. The diet of geophagic individuals is often high in phytate which, because of its nutrient binding ability, can potentially further decrease the bioavailability of $\mathrm{Fe}, \mathrm{Zn}$ and other nutrients (Lebrón, 2007). In a cross sectional study in an antenatal clinic at Kilifi district hospital in Kenya, Geissler et al. (1999) reported low Fe status and anaemia among $56 \%$ of pregnant women who practiced geophagia. Geophagic materials are also associated with transmission of worms and thus, geophagia poses health risks to consumers (Sera et al., 2004).

The prevalence of geophagia is unknown because the disorder is often unrecognised and underreported. In addition, reported prevalence rates vary depending on the characteristics of the population sample and the methods used for data collection (Yao, 2006). Individuals who practice geophagia normally withhold the information regarding it as a secret and often deny when questioned. A reluctance to report the practice and its secretiveness on the part of patients frequently interferes with accurate diagnosis and establishment of prevalence (Horner et al., 1991). Soil ingestion by geophagic individuals is however highly variable; reports range from a few grams to $300 \mathrm{~g}$ per day (Simon, 1998) leading to variations in $\mathrm{Pb}$ exposure levels. This study determined temporal $\mathrm{Pb}$ contamination levels in geophagic soils arising from exposure at selected geophagic soil vendors in Eldoret municipality and assessed health risks associated with ingestion of $\mathrm{Pb}$.

\section{MATERIALS AND METHODS}

\section{Study sites}

A preliminary study was done and involved determination of the sources (control) of geophagic soils sold in Eldoret Municipality. This was done by administering structured questionnaires to randomly selected soil vendors in the town. A visit was made to Gituro quarry, which is the major source of 
the geophagic soils. Gituro quarry is located about $4 \mathrm{~km}$ to the North of the central business district of Eldoret town, Uasin Gishu district in Rift Valley Province of Kenya, latitudes $0^{\circ} 25^{\prime} ; 0^{\circ} 31^{\prime} \mathrm{N}$, and longitudes $35^{\circ}$ $00^{\prime} ; 35^{\circ} 17^{\prime} \mathrm{E}$ of Greenwich (Figure 2). The quarry measures approximately $1 \mathrm{~km}^{2}$ and it is excavated mainly for construction materials bush stones and ballast. Geophagic soils are excavated within the quarry from shallow open pits ( $1 \mathrm{~m}$ deep) of approximately $100 \mathrm{~m}^{2}$. The soils are excavated and sized using hoes and transported to the markets in gunny bags.

\section{Geology of the soils}

The geology of the study area falls under volcanic system mainly constituting of volcanic rocks of tertiary age. The volcanic rocks are mainly of alkali type constituting of phonolites of the lower Uasin Gishu phonolite, and their pyroclastic equivalents (Jones and Lippard, 1979). The phonolites are aphanitic and blue-black in colour, with a pilotaxitic texture mainly consisting of aegirine, cossyrite and kataphorite with microphenocrysts of elongated soda orthoclase feldspars and accessory granules of apatite and iron ore.

Soils covering the phonolites are relatively thin with a friable texture. The soils are mainly brown loams occurring as platy particles in fine grained aggregates.

\section{Soil sampling}

Geophagic soils recipients in the markets namely Huruma, Langas and Eldoret Municipal market (Figure 2), were identified. Huruma and Langas residential estates were selected due to their high population density, whereas the main municipal market was selected since it acts as the main source of supply for other retailing soil vendors in most residential estates besides other consumer goods. Local women soil miners at the quarry were also identified, and based on their experience, two sampling sites were purposely selected based on soils characteristics (peoples' popularity craving and sour tastes).

The quarry soil types were collected in bulk using the same tools as the soil diggers, and dispatched to the pre-determined market vendors for determination of temporal $\mathrm{Pb}$ contamination in the markets. Soils with popular craving taste were supplied to one vendor each at Huruma estate, Langas and the Municipal market (1) respectively. The sour taste soils were supplied to second vendor at the Municipal market (2). The soils were exposed to the market conditions and not sold. From the unexposed Gituro quarry soil types (control), approximately $0.5 \mathrm{~kg}$ each, in duplicate, were sampled for determination of $\mathrm{Pb}$ concentration at source.

Sampling and analysis of geophagic soils was done fortnightly for a period of three consecutive months beginning from the month of June 2007 to August 2008. All the supplied quarry soil types were exposed to the same market vendors handling for the entire sampling period. A total of 60 samples, that is, 12 replicates from each of the five studied sites, were collected and analysed

\section{Laboratory and analytical methods}

The soil samples were oven dried at $55^{\circ} \mathrm{C}$ to constant weight and passed through a $0.2 \mathrm{~mm}$ aperture sieve. Two soils weighing $2.0 \mathrm{gm}$ were taken from sub-samples of each sampling site and accurately measured into digestion flasks. Ten millilitres of $69 \%$ nitric acid (analar grade) was added and the mixture shaken gently for 2 minutes. Four millilitres of concentrated hydrochloric acid (analytical reagent grade) was then added while continuing to shake. The mixture was transferred to a hot plate and heated for about 2 hours while controlling the temperature at $70^{\circ} \mathrm{C}$ until no more brown fumes evolved. Nitric acid was added whenever necessary to avoid the samples running dry. The heating was continued until a pale brown colour resulted indicating digestion was complete (Lewis and McConchie, 1994). 
The digests were cooled and extracts filtered through a $0.45 \mu \mathrm{m}$ filter paper into a pre-washed measuring cylinder. The residue on the filter papers was washed three times with de-ionised water and filtrate made to the $100 \mathrm{ml}$ mark with de-ionised water. Lead concentration in the digests was determined using an Atomic Absorption Spectrophotometer; Spectre F-AAS model Spectre AA 100/200 (IPCS, 1992).

Soil $\mathrm{Pb}$ concentration in $\mathrm{mg} / \mathrm{kg}$ was calculated from the $\mathrm{mg} / \mathrm{l}$ results by using the following formula:

Metal concentration $(\mathrm{mg} / \mathrm{kg})=(\mathrm{A} \times \mathrm{B}) \div \mathrm{g}$ (sample weight),

where: $\mathrm{A}=$ Concentration of metal in digested solution $(\mathrm{mg} / \mathrm{l})$ and $B=$ final volume of digested solution $(100 \mathrm{ml})$.

Standard solutions were prepared by dissolving $1 \mathrm{~g}$ of $99.99 \%$ pure standard of $\mathrm{Pb}$ into 1:1 nitric acid: de-ionised water by volume and made to $1000 \mathrm{ml}$ mark. This was used as stock solution to prepare $0.5,1$ and 2 $\mathrm{ppm}$ respectively of $\mathrm{Pb}$ metal for instrument calibration. De-ionised water was used to prepare blanks. Calibration of AAS was repeated after every 10 samples to ensure reliability of the results. Data was analysed by using 2-way ANOVA to determine significance (at 95\% confidence level) of variation of means in relation to time and sites.

\section{RESULTS \\ Lead concentrations of geophagic soils at source}

Lead concentrations in geophagic soils collected from Gituro quarry (source) are summarized in Table 1 . Least $\mathrm{Pb}$ concentration levels in popular graving soils were $31.5 \pm 1.7 \mathrm{mg} / \mathrm{kg}$ at sites $\mathrm{GP}_{2}$ and were relatively high with mean of $37.5 \pm 2.1 \mathrm{mg} / \mathrm{kg}$ at site $\mathrm{GP}_{3}$. The sour taste mean soil $\mathrm{Pb}$ concentrations were $39.5 \pm 3.3 \mathrm{mg} / \mathrm{kg}$ at $\mathrm{GS}_{1}$ and $41.0 \pm 5.1 \mathrm{mg} / \mathrm{kg}$ at site $\mathrm{GS}_{2}$. As is evidenced in Table 1, the sour taste soils with relatively higher lead concentrations were more acidic (low $\mathrm{pH}$ ).

However, comparison of means by ANOVA showed no significant difference ( $P$ $>0.05$ ) in the Gituro quarry soil $\mathrm{Pb}$ concentrations. Calculated mean concentration of $\mathrm{Pb}$ in bulked popular craving and sour geophagic soils at source were $34.5 \pm 3.2 \mathrm{mg} / \mathrm{kg}$ and $40.25 \pm 4.1$ respectively. These were above the EU 'normal' soil concentration values that range from less than 10-30 ppm Pb (EPA, 2001).

Upon exposure at the four market sites, all supplied geophagic soil samples (100\%) acquired significant amounts of $\mathrm{Pb}$ over and above the naturally occurring levels with time (Figure 3). A 2-way-ANOVA test of significance indicated that time $(\mathrm{F}=43.071$, $\mathrm{P}=0.000, \alpha=0.05)$ and site factors $(\mathrm{F}=10.625$, $P=0.000, \alpha=0.05$ ) had significant effects on enrichment of $\mathrm{Pb}$ in the market exposed geophagic materials. Tukey's Post hoc test of homogeneity showed that geophagic soil samples from Langas were contaminated more than the soils from other experimental sites.

Table 1: $\mathrm{pH}$ and mean $\mathrm{Pb}$ concentration levels for unexposed popular craving and sour soil samples from Gituro quarry.

\begin{tabular}{lccccc}
\hline Sample & $\mathbf{G P}_{\mathbf{1}}$ & $\mathbf{G P}_{\mathbf{2}}$ & $\mathbf{G P}_{\mathbf{3}}$ & $\mathbf{G S}_{\mathbf{1}}$ & $\mathbf{G S}_{\mathbf{2}}$ \\
$\mathrm{pH}$ & 6.43 & 5.85 & 5.33 & 5.05 & 5.80 \\
$\mathrm{~Pb}(\mathrm{mg} / \mathrm{kg})$ & $32.5 \pm 2.2^{\mathrm{a}}$ & $31.5 \pm 1.7^{\mathrm{a}}$ & $37.5 \pm 2.1^{\mathrm{a}}$ & $39.5 \pm 3.3^{\mathrm{a}}$ & $41.0 \pm 5.1^{\mathrm{a}}$ \\
\hline
\end{tabular}

Values of $\mathrm{Pb}$ are Mean \pm SD of 12 determinations; $\mathrm{a}=$ no significant difference within $95 \%$ confidence level; $\mathrm{Pb}=$ lead ; $\mathrm{GP}_{1}=$ Gituro Popular soil site one; $\mathrm{GP}_{2}=$ Gituro Popular soil site two; $\mathrm{GP}_{3}=$ Gituro Popular soil site three; $\mathrm{GS}_{1}=\mathrm{Gituro}$ Sour soil site one; $\mathrm{GS}_{2}=$ Gituro Sour soil site two. 
Table 2: Amount of $\mathrm{Pb}$ taken by persons practicing geophagia and their percentage to PTWI for popular craving soils.

\begin{tabular}{lllll}
\hline $\begin{array}{l}\text { Pb concentrations in } \\
\text { soil }(\mathbf{m g} / \mathbf{k g})\end{array}$ & $\begin{array}{l}\text { Amount of excess } \\
\text { Pb per week }(\boldsymbol{\mu g})\end{array}$ & $\begin{array}{l}\text { Calculated } \\
\text { PTWI }\end{array}$ & $\begin{array}{l}\text { \% of heavy metal } \\
\text { to PTWI Pb }\end{array}$ \\
Least $\quad 36.5$ & 784.4 & 13.1 & 52.4 \\
Highest $\quad 98.0$ & 18650.1 & 310.8 & 1243.2 \\
\hline PTWI = Provisional Tolerable Weekly Intake & &
\end{tabular}

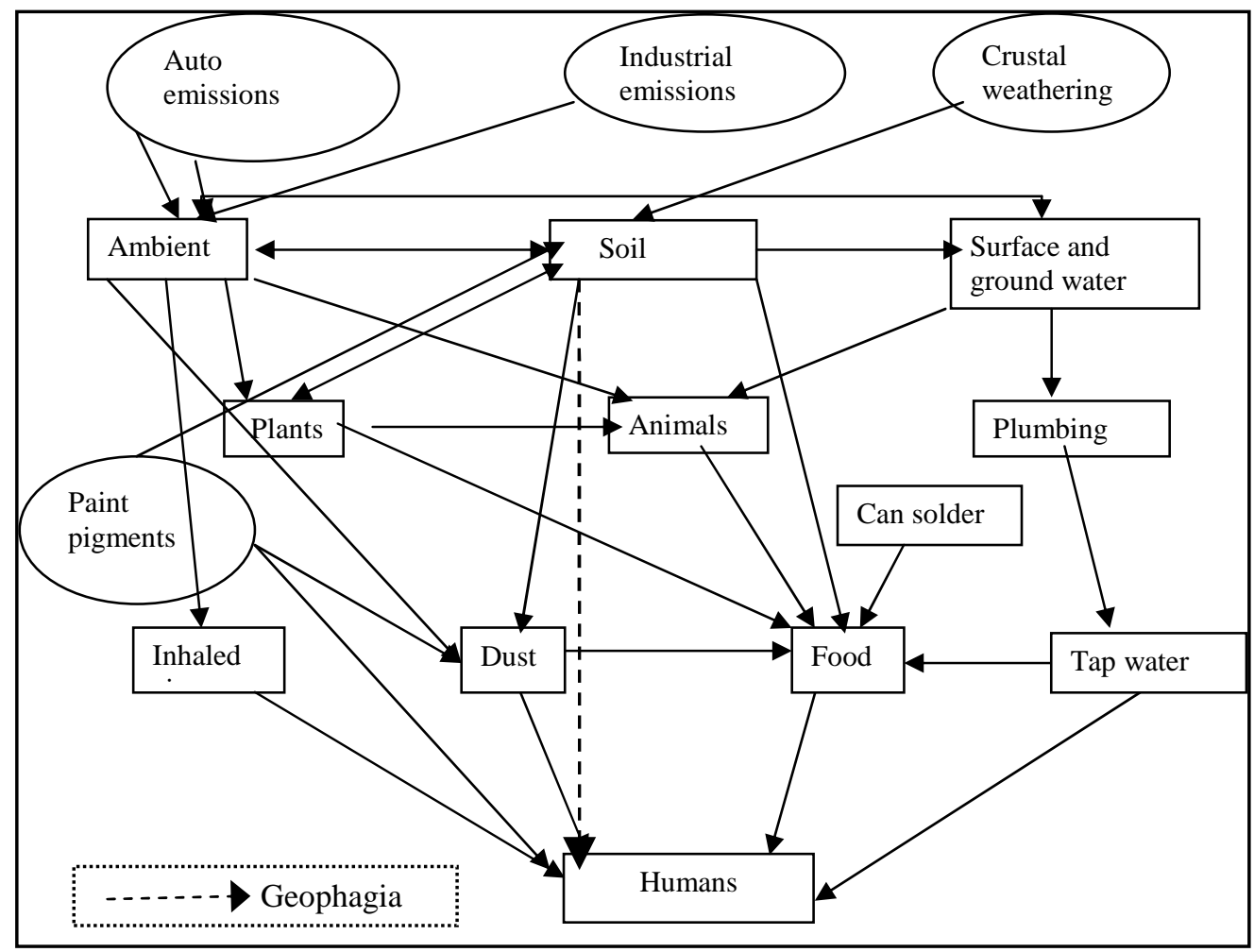

Figure 1: Flow scheme for $\mathrm{Pb}$ in the environment along pathways for human exposure. Adopted from Mushak (1998). 


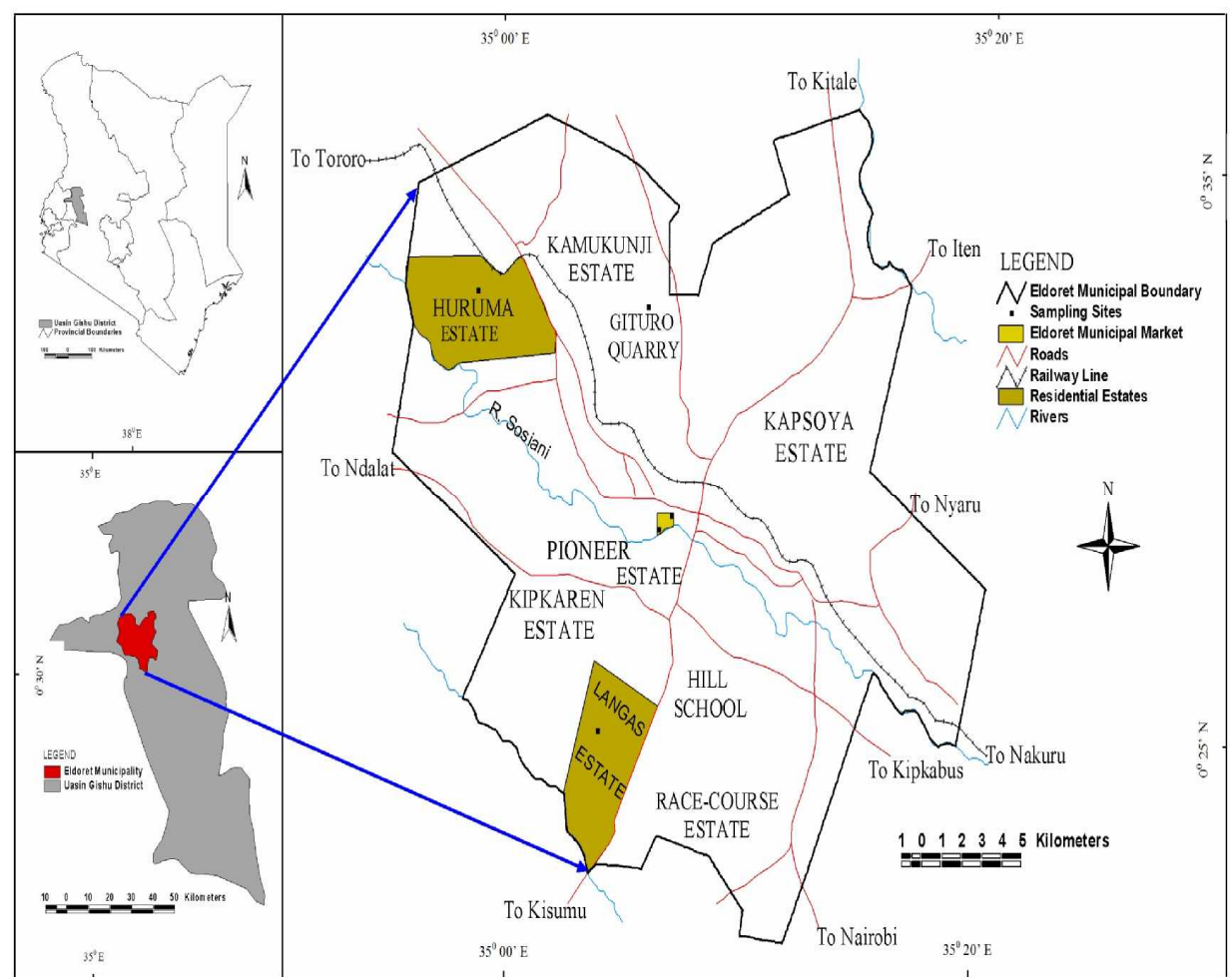

Figure 2: A map of Kenya showing Uasin Gishu district, and the location of the study areas in Eldoret Municipality and Gituro Quarry (source of the study geophagic soils).

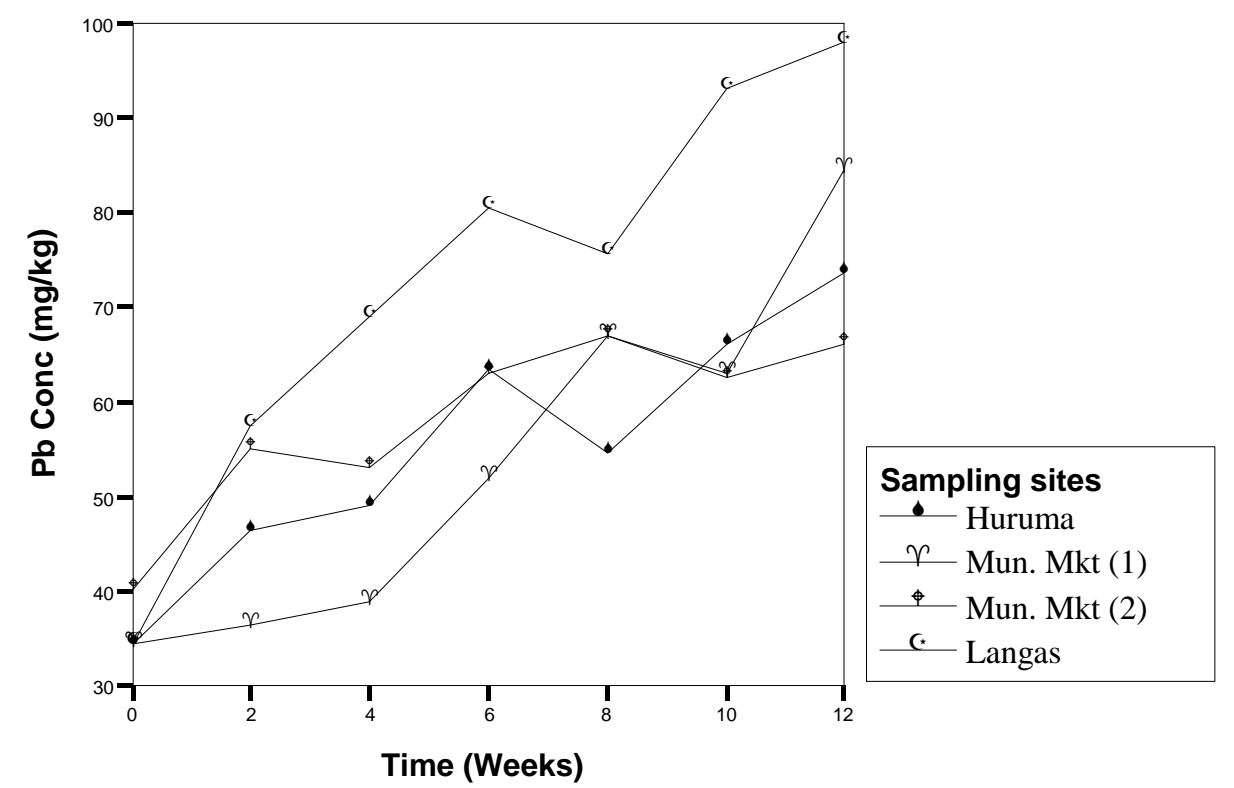

Figure 3: Temporal variations of $\mathrm{Pb}$ concentrations in exposed geophagic soils supplied to vendors at selected sites in Eldoret municipality.

Mun. Mkt (1) = Municipal Market site one; Mun. Mkt (2) = Municipal Market site two. 


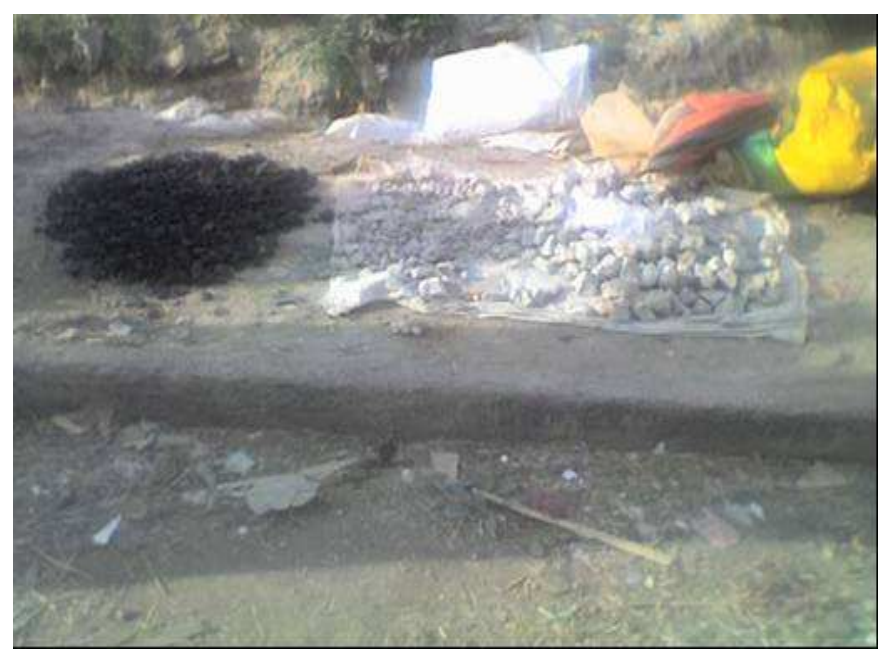

Figure 4: Exposed geophagic soils in Eldoret municipality. Notice the proximity of the soils to the roadside.

\section{DISCUSION}

As evidenced from the study results, $\mathrm{Pb}$ concentration in geophagic materials at source are relatively higher than normal. However, the $\mathrm{pb}$ concentrations in Gituro geophagic soils are much less compared to polluted soils, for example, in Nairobi (mean of $659 \mathrm{mg} / \mathrm{kg}$ $\mathrm{Pb}$ ) (Onyari et al., 1991). Conversely, the calculated means $\mathrm{Pb}$ concentration levels in popular craving and sour geophagic soils at source are attributable to natural geochemistry of the soils at the quarry. This is expected given the ubiquitous nature of $\mathrm{Pb}$ in the environment (NTDS, 2000). Exposure of geophagic materials exacerbates pb contamination levels as was established in Langas geophagic soil materials.

The steep rise of $\mathrm{Pb}$ levels $\left(\mathrm{R}^{2}=0.916\right)$ in samples from Langas is probably due to vehicular emissions, since this is a very busy town service bus terminus and geophagic soils are sold exposed at the road sides (Figure 4). According to Kunguru and Tole (1994) soils samples from road verges were contaminated with $\mathrm{Pb}$, which they attributed to motor vehicle emissions. Furthermore, Jua Kali (Open-air Artisan Works) activities thrive at Langas site; $\mathrm{Pb}$ contamination from paints, especially due to dust could be a possibility.

\section{Health risks}

Continuous ingestion of $\mathrm{Pb}$ contaminated soils may be risky to human health particularly if consumption rates exceed the Provisional Tolerable Weekly Intake (PTWI). Soil ingestion by geophagic individuals however is highly variable; reports range from a few grams per day to $300 \mathrm{~g}$ per day (Simon, 1998) leading to variations in $\mathrm{Pb}$ exposure levels. While information concerning permissible levels of $\mathrm{Pb}$ in geophagic soils is not yet available, geophagia is rampant and there is need to address its health implications.

Lead concentrations from analysed geophagic soils were used in risk analysis based on the assumptions that PTWI adopted from $\mathrm{FAO} / \mathrm{WHO}$ recommendation is $25 \mu \mathrm{g} / \mathrm{kg}$ body weight of $\mathrm{Pb}$ (IPCS, 1992; FAO/WHO, 1986), that average adult female weighs 60 $\mathrm{kg}$ ), and that on average women consume 41.5 g/day of geophagic soils (Geissler et al., 1999). The human health risk assessment was estimated by comparing the metal intake from the consumption rate of geophagic soils with the PTWI.

The amount of $\mathrm{Pb}$ taken weekly by an adult person from the exposed geophagic soils (i.e. in excess of the soils $\mathrm{Pb}$ levels at source), 
was calculated according to Bernhard (1982) and Nyamari and Simiyu (2007).

The estimated geophagic exposures for $\mathrm{Pb}$ in $\mu \mathrm{g} / \mathrm{kg}$ body weight, based on the least (36.5 mg/kg Pb, at Municipal market site 1) and highest (98.0 mg/kg $\mathrm{Pb}$ at Langas) concentration levels are presented in Table 2. The excess weekly $\mathrm{Pb}$ ingested from least contaminated geophagic soils at the vendors' stocks is $52.4 \%$ of the PTWI values, which is less by more than half. However, in case of the worst scenario, Langas site, the excess weekly $\mathrm{Pb}$ ingested significantly $(1243.2 \%)$ surpassed the PTWI values. This indicated that exposed geophagic soils at the busy bus terminus could pose higher $\mathrm{Pb}$ health risks.

Whether there is no $\mathrm{Pb}$ health risk for the human consumption of geophagic soils at source may not be inferred with certainty since the percentage of $\mathrm{Pb}$ bioavailability was not determined. Similarly for geophagic soils or clays currently packaged and sold in supermarkets. Although they are less exposed to contaminating environments, their source and $\mathrm{Pb}$ concentration levels are uncertain. Thus, there could be a potential danger depending on the source and the amount of soils consumed from such markets. There is need for caution because according to NTDS (2000), there is no established "no effect level" for $\mathrm{Pb}$ in animals or humans and its ubiquitous nature precludes it from complete elimination from foods.

\section{Conclusions}

Results of this study showed that geophagic soils sold in Eldoret municipality open markets, particularly Langas estate, are contaminated with $\mathrm{Pb}$. The $\mathrm{Pb}$ contamination could be emanating from environmental sources including vehicular emissions. The $\mathrm{Pb}$ concentrations levels in geophagic soils tended to increase with time of exposure and location of the sample in the market.

It is discernable that ingesting exposed soils sourced from an urban setting and close to roads characterised by heavy traffic is a potential health risk to consumers. Potential clinical implications associated with consumption of $\mathrm{Pb}$ contaminated geophagic materials, especially on expectant women and the unborn foetus should be assessed since they are most vulnerable considering prevalent geophagia among women. Packaging and healthy handling of geophagic soils is recommended to minimise $\mathrm{Pb}$ exposure risks for consumers. There is also need for education awareness to sensitise the public on risks of consuming geophagic materials.

\section{ACKNOWLEDGEMENTS}

The authors would like to thank Kerio Valley Development Authority, the women vendors in Eldoret and in Gituro quarry and the manager of Gituro quarry for logistics and technical support.

\section{REFERENCES}

Abrahim GMS, Parker RJ. 2008. Assessment of heavy metal enrichment factors and the degree of contamination in marine sediments from Tamaki Estuary, Auckland, New Zealand. Journal of Environmental Monitoring and Assessment, 136(1-3): 227-238.

Atkinson R, Bremner S, Anderson H, Strachan D, Bland JM. 1999. Short- term association between emergency hospital admissions for respiratory and cardiovascular disease and outdoor air pollution in London. Arch. Environ. Health, 54(6): 399-411.

Bernhard M. 1982. Levels of trace metals in the Mediterranean, Ves. J. Etud. Pollut., Cannes, C.I.E.S.M., 237-243.

Ellen G. 1993. The importance of quality assurance in trace elements. Proceedings of the $18^{\text {th }}$ May 1992 International Seminar. 9302, Southrofan-Germany. IDF Press; 129.

EPA (Environmental Protection Agency) 2001. Human Health Fact Sheet. American News Letter.

FAO/WHO 1986. Exposure of Infants and Children to Lead. FAO Food and Nutrition. The working document for $30^{\text {th }}$ 
meeting of the JECFA. Uppsala, Sweden; 45.

Geissler PW, Prince RJ, Levene M, Poda C, Beckerleg SE, Mutemi W, Shulman CE. 1999. Perceptions of soil eating and anaemia among pregnant women on the coast of Kenya. Soc. Sci. Med., 48(8): 1069-1079.

Hooda PS, Henry CK, Seyoum TA, Armstrong LDM, Fowler MB. 2002. The potential impact of geophagia on the bioavailability of iron, zinc and calcium in human nutrition. Environmental Geochemistry and Health, 24(4): 305319.

Horner RD, Lackey CJ, Kolash K, Warren K. 1991. Pica Practices of Pregnant Women, J. Am. Diet Assoc., 91: 34-38.

IPCS (International Program on Chemical Safety) (1992). Lead Environmental Health Criteria, 85. World Health Organization: Geneva.

Jones WB, Lippard SJ. 1979. New age determinations and the geology of the Kenya Rift-Kavirondo Rift Junction. Journal of Geological Society, 136(6): 693-704.

Kunguru KK, Tole MP. 1994. Contamination of soils, maize, wheat and milk with lead motor vehicle emissions in Uasin Gishu district, Kenya. Discovery and Innovation, 6(3): 26-33.

Lebrón M, Rodríguez-Sierra CJ, Ortiz AP, Mansilla-Rivera I. 2007. Association of Placental $\mathrm{Cd}$ and $\mathrm{Pb}$ with Newborn Anthropometric Measurements. Epidemiology: ISEE 2007 Conference Abstracts Supplement. 18(5); S195.

Lewis DW, McConchie DM. 1994. Analytical Sedimentology. Chapman and Hall: New York.
Mushak P. 1998. Uses and Limits of Empirical Data in Measuring and Mapping Human Exposure. Environmental Health Perspective, 106(6): 1467-1484.

NTDS (New Zealand Total Dietary Survey) 2000. Lead contamination of food products, Ministry of Health Report, New Zealand.

Nyamari JM, Simiyu GM. 2007. Urban livestock and potential human health risks in Eldoret town, Kenya. Journal of Building and Land Development, 14(2):100-107.

Onyari JM, Wandiga SO, Njenga GK, Nyatebe JO. 1991. Lead contamination in Street soils at Nairobi and Mombasa Island, Kenya. Bulletin Contam. Toxicol., 46:782-789.

Sera LY, Goodman D, Tamer HF, Said MA, Khatib MR, Sabra SK, Tielsch JM, Stoltzfus RJ. 2007. Association of geophagia with Ascaris, Trichuris and hookworm transmission in Zanzibar, Tanzania. J. Trans. R. Soc. Trop. Med. Hyg., 101(8): 766-772.

Simon SL. 1998. Soil ingestion by humans: a review of history, data, and aetiology with application to risk assessment of radioactively contaminated soil. Health Physic, 74: 647- 672.

Wiley AS, Katz SH. 1998. Geophagy in pregnancy: a test of a hypothesis. Current Anthropology, 39: 532-545.

Yao P. 2006. Clinical Vignette: A Case of Geophagia. Proceedings of UCLA HealthCare Vol. 10, 2006, UCLA Department of Medicine, USA. 